\author{
Elif Yalcin*, Suna Kose and Mufit \\ Akyuz \\ Ankara Physical Medicine and Rehabilitation Training and \\ Research Hospital, Turkey \\ Dates: Received: 04 November, 2014; Accepted: \\ 17 March, 2015; Published: 19 March, 2015 \\ *Corresponding author: Elif Yalcin, Ankara Physical \\ Medicine and Rehabilitation Training and Research \\ Hospital, Turkey, Tel: 0505 3749467; E-mail: \\ elifyalcin78@gmail.com \\ www.peertechz.com \\ ISSN: 2455-5487
}

Keywords: Gluteal injections; Ultrasound; Siatic nerve injury

\section{Research Article \\ Comparing the Distances of Different Intramuscular Gluteal Injection Sites to the Sciatic Nerve}

\section{Introduction}

It is known that for gluteal injections the upper outer quadrant is the safest area. The two most commonly referenced intramuscular injection sites are the dorsogluteal, ventrogluteal sides in the gluteal region for adults. Historically the dorsogluteal injection side is the main side for injection. This site been used by nurses for years as the target of choice for intramuscular injections. There is a wide agreement in the literature that the ventrogluteal site is much more preferable [1]. The goal of this paper is to identify the more safety place for gluteal injections according to the distance of these two injection sites to the sciatic nerve at the gluteal region and the muscle thicknesses at these injection sites.

\section{Materials and Methods}

There were 25 participants who were prescribed intramuscular treatment with a body mass index $<22$, recruited from outpatient clinic between January-March 2014. The goal to select the patients with BMI lower than 22, was that those people with lower body mass indexes have a higher risk for siatic injury during injections. The patients with gluteal trauma, burn or surgical intervention were excluded. After informed consents were obtained, the routine injection side in the dorsogluteal region was determined and marked by an experienced nurse. Then the sciatic nerve has been evaluated using a linear array probe (7-12 MHz Logiq P5a) at the entrance point under the piriformis muscle. The distance between these two points has been measured and recorded. The muscle thickness (gluteus maximus) at this injection side also measured ultra sonographically.

At the second step of our study, a more safe and advisable injection side has been determined at the ventrogluteal region (gluteus medius and minimus muscle) under the iliac crest. The distances of this second injection point to the siatic nerve under the piriformis muscle have also been measured. Also for standardization the distance of this advised point to the spinal iliaca anterior superior have also been measured. The muscle thicknesses at this point have also been measured ultrasonographically.

\section{Results}

The results were evaluated by SPSS statistical software programme. Mann-Whitney $U$ test were used to compare the differences. Eleven of the patients were woman, and 14 of them were men. The mean age of the participant was $37 \pm 13$ and the mean BMI were $18 \pm 2.5$ $\mathrm{kg}$. The mean distance between the dorsogluteal injection points to the siatic nerve under the piriformis muscle is $9 \pm 2.3 \mathrm{~cm}$. The mean muscle thickness at this point was $22 \pm 5.6 \mathrm{~cm}$. The mean distance of the second more advisable and safe injection point at ventrogluteal side to the siatic nerve was $18 \pm 3.5 \mathrm{~cm}$. The mean muscle thickness at this point is $24 \pm 6.5 \mathrm{~mm}$. The distance of this point to the spina iliaca anterior superior obliquely is $9.5 \pm 2.2 \mathrm{~cm}$. There was a significant difference between the distance to the sciatic nerve of dorsogluteal and ventrogluteal injection sites while no significant differences 
were found between the muscle thickness of the ventrogluteal and dorsogluteal injections sites.

\section{Discussion}

This study revealed that the mean distance of the dorsogluteal injection point to the siatic nerve is $9 \pm 2.3 \mathrm{~cm}$. This point seems very safe to inject but in emergency cases and in unstable patients small deflections could cause siatic nerve injuries. On the other hand ventrogluteal injection side seems more safe, measurable and more distant $(18 \pm 3.5 \mathrm{~cm})$ to the sciatic nerve.

It is known that the muscle thickness at the injection side is important for emulsion of the drugs. No statistical difference has been found between the muscle thickness of the ventrogluteal and dorsogluteal injections sites $(\mathrm{p}<0.01)$. This means both of these injection points have similar emulsion properties for intramuscular gluteal injections.

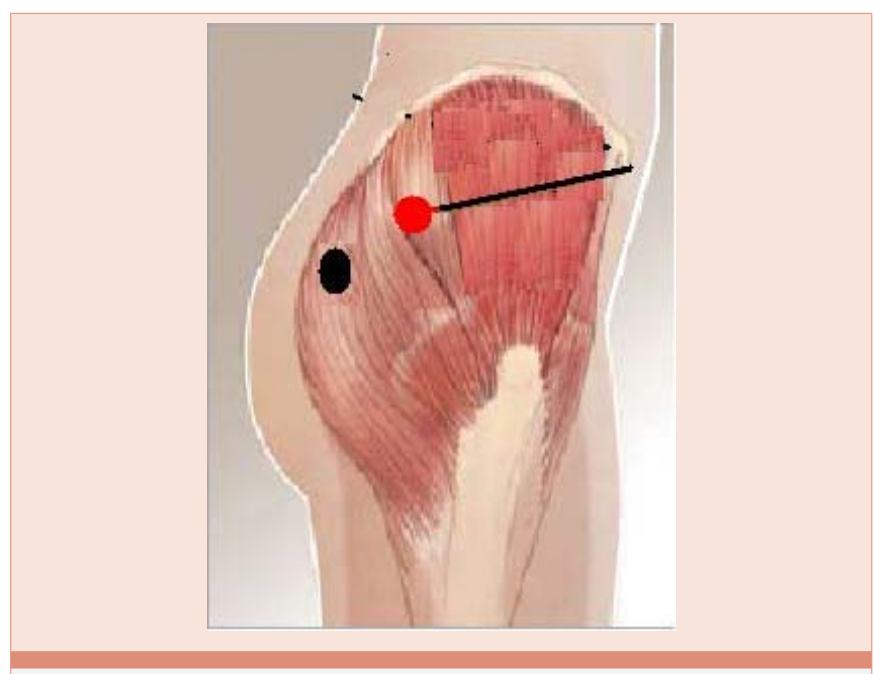

Figure 1: The red circular area represents the ventrogluteal injection site, while the black one represents the dorsogluteal injection point. The black line indicates the distance of the ventrogluteal site to the anterior superior iliac spine.
There are different sites for injection such as thigh, deltoid, dorsogluteal and ventrogluteal site. All of them have some advantages and disadvantages to each other. For dorsogluteal injections, the sciatic nerve and superior gluteal artery lies very near to the injection site, so great caution should be taken during the procedure. On the other hand, the ventrogluteal side has a thicker gluteal muscle layer and thinner fat layer and is free of penetrating nerves and blood vessels [4]. Studies have shown that adults with lower BMI and children have a higher risk of injury because of a thinner gluteal fat pad [2]. Especially for this kind of patients, it is better to choose an alternative injection site rather than dorsogluteal point. Also in many guidelines this dorsogluteal site is contraindicated for children. But traditionally in many settings dorsogluteal site is the first choice to inject. There is a need to give appropriate education about the alternative more rarely used injections sites to avoid many complications.

\section{Conclusion}

In conclusion, in emergency services there is huge workload with many painful and agitated patients and in these cases accidental events could occur. It seems the ventrogluteal injection site just 9-10 $\mathrm{cm}$ distant to spina iliaca anterior inside of the gluteus medius muscle seems a more convenient and measurable injection site to prevent a siatic nerve injury.

\section{Conflict of Interest}

There is no conflict of interest with any financial organization.

\section{References}

1. Small SP (2004) Preventing sciatic nerve injury from intramuscular injections: literatureReview. J AdvNurs 47:287-296.

2. Akyuz M, Turhan N (2006) Post injection sciatic neuropathy in adult. ClinNeurophysiol 117:1630-1635.

3. Ramtahal J, Ramlakhan S, Singh K (2006) Sciatic Nerve Injury Following Intramuscular Injection: A Case Report and Review of the literature. J NeurosciNurs 38:238-240.

4. Zelman S (1961) Notes on techniques of intramuscular injection. The avoidance of needless pain and morbidity.Am J Med Sc 241: 563-574. 